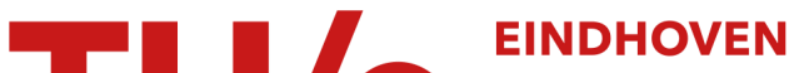 UNIVERSITY OF TECHNOLOGY
}

\section{Considerations for a photonic beamformer using an LFM waveform in transmit}

\section{Citation for published version (APA):}

Rotman, R., Raz, O., \& Tur, M. (2004). Considerations for a photonic beamformer using an LFM waveform in transmit. In Proceedings of the IEEE Antennas and Propagation Society Society International Symposium, 2004, 20-25 June 2004, Monterey, California (Vol. 4, pp. 4332-4335). Institute of Electrical and Electronics Engineers. https://doi.org/10.1109/APS.2004.1330310

DOI:

10.1109/APS.2004.1330310

Document status and date:

Published: 01/01/2004

\section{Document Version:}

Publisher's PDF, also known as Version of Record (includes final page, issue and volume numbers)

\section{Please check the document version of this publication:}

- A submitted manuscript is the version of the article upon submission and before peer-review. There can be important differences between the submitted version and the official published version of record. People interested in the research are advised to contact the author for the final version of the publication, or visit the $\mathrm{DOI}$ to the publisher's website.

- The final author version and the galley proof are versions of the publication after peer review.

- The final published version features the final layout of the paper including the volume, issue and page numbers.

Link to publication

\section{General rights}

Copyright and moral rights for the publications made accessible in the public portal are retained by the authors and/or other copyright owners and it is a condition of accessing publications that users recognise and abide by the legal requirements associated with these rights.

- Users may download and print one copy of any publication from the public portal for the purpose of private study or research.

- You may not further distribute the material or use it for any profit-making activity or commercial gain

- You may freely distribute the URL identifying the publication in the public portal.

If the publication is distributed under the terms of Article $25 \mathrm{fa}$ of the Dutch Copyright Act, indicated by the "Taverne" license above, please follow below link for the End User Agreement:

www.tue.nl/taverne

\section{Take down policy}

If you believe that this document breaches copyright please contact us at:

openaccess@tue.nl

providing details and we will investigate your claim. 


\section{Considerations for a Photonic Beamformer using an LFM Waveform in Transmit}

R. Rotman*, O. Raz, and M. Tur

Faculty Of Engineering, Tel-Aviv University, Tel Aviv, Israel

e-mail:rotman@eng.tau.ac.il, Tel: +972-3-6407374, Fax: +972-3-6410189

Introduction

Photonic beamformers [1] are candidates for inclusion within wideband RF systerns [2] such as that of imaging radar, which need true time delay. These radars have increasingly stringent requirements as to their performance within the RF bandwidth. In receive, the feasibility of optical links are at present inherently limited by intermodulations caused by the modulator, the need for large dynamic range and the need to maintain linearity. These problems are difficult to solve with present technology. However, when dealing with a Transmitter (Tx) photonic beamformer, which provides TTD to a set of subarrays with either phase or timeshifters, and using LFM waveforms, there exists mapping between a single instantaneous frequency for every instant of time in the pulse. Therefore, the requirements of linearity and dynamic range are far less rigorous and the transmit link can work at high modulation indices (non-linear regime of the modulator), allowing high $\mathrm{S} / \mathrm{N}$ and reasonably low loss-not an option in receive. The phase shifter in the subarray allows a certain amount of calibration of the optical beamformers. Moreover, the progress in erbium amplifiers also greatly mitigates the problems of $\mathrm{S} / \mathrm{N}$ and loss within the link. The following paper extends the analysis of the CW link for a linear frequency modulated pulse (LFM). It examines the problems of loss, $\mathrm{S} / \mathrm{N}$ and phase and amplitude ripple, and shows that using COTS elements, a Tx LFM beamformer can be constructed, which satisfies many radar requirements.

\section{LFM Optical Beamformer--System}

The system, which we analyze, comprises a transmit exciter, which is the RF input to a DSB electro-optic modulator. The optical signal is provided by a tunable laser. The signal then goes to an erbium doped fiber optical, an optical filter and is split to 20 subarrays. Each subarray path has its own TTD device. The true time delay is achieved via a WDM device, where by varying the optical frequency, a different path length (time delay) is chosen. The time delays are thus discrete and are limited to the number achievable in today's WDMs ( $>100$ channels). The WDM was chosen as the true time delay device rather than dispersive fibers, because it is inherently less temperature sensitive than dispersive optical fibers and avoids the problem of amplitude fading. It also suffers from much less amplitude and phase ripples relative to Bragg gratings. The signal is then sent for direct detection by a photodiode at the input of each subarray. In receive, we assume either digital or analog beamforming (Fig. 1).

\section{Analysis of LFM Pulse Distortion after Optical Component}

The next section analyzes the distortion caused by the optical components in the Tx beamformer on an LFM pulse. Optical components were shown in previous works to have an equivalent RF transfer function [3]. The analysis then becomes identical to that of the equivalent $R F$ filter applied to the LFM pulse as we now demonstrate. An LFM signal is defined $\mathrm{E}(\mathrm{t})=\cos \left(\omega_{0} \mathrm{t}+\mathrm{B} / 2 \mathrm{Tt}^{2}\right) \operatorname{rec}[\mathrm{t} / \mathrm{T}]$, where $B$ is the total bandwidth of the signal and $T$ is the pulse length. At time $t_{t}, \omega_{\text {mut }}=\omega_{0}+(B / T) t_{1}$. As is well known [4], there is an exact mapping between instantaneous frequency and time in the pulse. Therefore, if the LFM pulse goes through a non-linear device, it will produce harmonics but not intermodulations-a mitigating factor. The Fourier transform of $E(t)$ is appproximately $E(\omega) \propto \exp \left(-i T / 2 B^{*}\left(\omega-\omega_{0}\right)^{2}\right.$ rect $\left[\left(\omega-\omega_{0}\right) / B\right]$ for $B T / 2 \pi>100$. After transversing an RF filter of the form $H(\omega)=A(\omega) \exp (i \phi(\omega))$, the output E-field becomes

$$
\begin{gathered}
E_{\omega m}(\omega) \propto A(\omega) \exp \left(-i T / 2 B\left(\omega-\omega_{0}\right)^{2}+i \phi(\omega)\right) \operatorname{rect}\left[\left(\omega-\omega_{0}\right) / B\right] \\
E_{\text {nem }}\left(t_{1}\right) \approx \int_{-8 / 2}^{B / 2} A(\omega) \exp \left(-i T / 2 B\left(\omega-\omega_{0}\right)^{2}+i \phi(\omega)\right) \exp \left(i \omega t_{i}\right) \operatorname{rect}\left[\left(\omega-\omega_{0}\right) / B\right] \mathrm{d} \omega
\end{gathered}
$$

0-7803-8302-8/04/\$20.00 @2004 IEEE 4332 
Since the phase of the integral in (L) will be oscillating rapidly, the method of stationary phase [4] can be applied if a stationary point is found. This will occur when $\partial\left\{\left(-\mathrm{T} / 2 \mathrm{~B} \omega^{2}+\omega \mathrm{t}_{\mathrm{i}}\right) / 2 \omega=0, \omega_{i}=\mathrm{t}_{\mathrm{j}} \mathrm{B} / \mathrm{T}+\omega_{0}\right.$ under the assumption that $\phi(\omega)$ is a slowly varying function relative to $T / 2 B\left(\omega-\omega_{0}\right)^{2}$. The dominant contribution to integral (1) is then found by evaluating the integrand at this single point. and

$$
\mathrm{E}_{\text {aew }}\left(\mathrm{t}_{\mathrm{i}}\right) \approx \mathrm{A}\left(\omega_{\text {ins }_{\mathrm{i}}}\right) \cos \left(\omega_{0} \mathrm{t}_{\mathrm{i}}+\mathrm{B} / 2 \mathrm{Tt}_{\mathrm{i}}^{2}+\phi\left(\omega_{\text {inst }}\right)\right) \operatorname{rect}[\mathrm{t} / \mathrm{T}]
$$

The signal then undergoes weighted matched filter processing (or dechirp processing). The magnitude of the ripples in $A(\omega)$ and $\phi(\omega)$ define what resolution and sidelobe level are achievable by the imaging system We now apply similar analysis to the optical link. The LFM signal is assumed to be double sideband modulated. The electrical optical field comprises a component at the optical carrier frequency $\omega_{\mathrm{r}}$, the two sidebands due to the RF signal at frequencies $\omega_{c} \pm \omega_{k F}$ and a series of harmonics at frequencies $\omega_{c} \pm n \omega_{k}$ For small modulation depth, $m$, when the modulator is used in the linear region, the harmonics are usually negligible and smail signal analysis can be applied. The output optical intensity (proportional to RF current) depends on the mixing of the carrier and the fundamental. Altematively, if the signal is at a high enough frequency ( $6 \mathrm{GHz}$ and higher), present day optical filters have narrow enough bandwidths to filter out the harmonics and the same analysis can be used. Otherwise, for higher modulation indices, the phase and amplitude fluctuations of the RF transfer function increase as the intensity depends on the summation of the mixing of the harmonics spaced $\omega_{\mathrm{RF}}$ apart. Initially, we assumed an LFM signal traveling through an optical filter of constant amplitude with only phase ripple, $H\left(\omega_{\mathrm{opl}}\right)=\exp \left(i \varphi\left(\omega_{\mathrm{opl}}\right)\right)$, and used small signal analysis . It has been shown that [3] for small $m$,

$$
\begin{aligned}
& \mathrm{I}\left(\mathrm{t}_{\mathrm{i}}\right) \approx \mathrm{K}(\mathrm{m}) *{ }^{*} \mathrm{r}\left(\exp \left(j \Phi_{\text {amp }}\left(\omega_{0}+\mathrm{B} / \mathrm{T}^{*} \mathrm{t}_{\mathrm{j}}\right)\right) * \cos \left(\omega_{0} \mathrm{t}+\mathrm{B} / \mathrm{T}^{*} \mathrm{t}_{\mathrm{i}}{ }^{2}+\Phi_{\text {phast }}\left(\omega_{0}+\mathrm{B} / \mathrm{T}^{*} \mathrm{t}_{\mathrm{i}}\right)\right]\right. \\
& \Phi_{\text {avp }}\left(\omega_{\mathrm{RF}}\right)=\left(\varphi\left(\omega_{\mathrm{c}}+\omega_{\mathrm{RF}}\right)+\varphi\left(\omega_{\mathrm{c}}-\omega_{\mathrm{RF}}\right)-2 \varphi\left(\omega_{\mathrm{c}}\right)\right) / 2 \\
& \Phi_{\text {phase }}\left(\omega_{R F}\right)=\left(\varphi\left(\omega_{c}+\omega_{R F}\right)-\varphi\left(\omega_{c}-\omega_{R F}\right)\right) / 2
\end{aligned}
$$

Equation 2 can now be directly applied with $A(\omega)=\cos \left(\Phi_{-m}(\omega)\right)$, and $\phi(\omega)=\Phi_{\text {max }}(\omega) . K(m)$, the amplitude of the output intensity is a function of the modulation depth. When $\Phi_{-m p}\left(2 \pi f_{v *}+B / T^{*} t_{i}\right)=\pi / 2, J\left(t_{i}\right)=0$. This is the well known phenomenon known in analog transmission of amplitude fading and occurs with devices of large constant dispersion-i.e, dispersive fibers. Although there have been attempts to solve this problem with single sideband modulation, the RF transfer function then becomes directly dependent on the optical phase which is problematic. Also of interest is how the system reacts to sinusoidal type ripples found in optical devices such as Bragg gratings. In the dechirping processing of the LFM signal, these ripples will affect the output temporal impulse response[5]: slow fluctuations of the phase error (with respect to the pulse bandwidth) will broaden the impulse response, while relatively fast sinusoidal fluctuations $(B>2 P)$ raise the sidelobe level. The number of cycles per pulse width for fast sinusoidal fluctuations does not affect the sidelobe level-only the position of the sidelobe relative to the main lobe. When the optical filter has an amplitude ripple, $\mathrm{H}\left(\omega_{\text {opt }}\right)=\mathrm{D}\left(\omega_{\mathrm{opt}}\right) \exp \left(\mathrm{i} \varphi\left(\omega_{\mathrm{opp}}\right)\right)$, the situation is more complex but can be handled with similar analysis using the equations found in [6]

\section{Simulation and Measurement}

A numerical simulation to check these results was done in a general way, including accurate modeling of the modulator and the optical channel, as well as the imaging algorythm.

As an example, a DSB optical link was simulated incorporating an optical device with transfer function

$$
H\left(\omega_{\text {op }}\right)=\left(1+A \cos \left[\frac{2 \pi}{P_{\omega}}\left(\omega_{\omega t}-\omega_{c}\right)+\theta_{1}\right]\right) \exp \left[j \pi / 180^{*} C \cos \left[\frac{2 \pi}{P_{\omega}}\left(\omega_{\omega}-\omega_{c}\right)+\theta_{c}\right]\right]
$$

with $C$ ranging from 2 to 8 degrees, and $A=.028,( \pm .25 \mathrm{~dB})$ was simulated assuming an RF LFM input for $B=4 P, \theta_{\Lambda}, \theta_{c}=\pi / 4$. The distorted signal is then correlated with the initial LFM pulse and compared to the ideal impulse response with a weighted filter designed to give $-40 \mathrm{~dB}$ sidelobes. Figure 2 shows the peak sidelobe level of the LFM pulse for both modulation depths of 0.1 and 1 . In the case of the higher modulation, we did not filter out the harmonics. The impulse response deteriorates slightly with higher modulation depth, but for many analyses, a small signal analysis would probably be a good starting point 
even for a modulation depth of 1 . The results were then compared to a simulation using Equation 2 . The error in computing the peak sidelobe of the impulse response using the transfer function was always less than $0.5 \mathrm{~dB}$ for sinisuidal phase fluctuations with amplitude less than 8 degrees. Because of the deterioration of the impulse response and also the deterioration of the spatial pattern, that occur even for small optical phase ripple, we determined that WDM devices which have insignificant phase ripple have an advantage over TTD devices such as Bragg gratings and was used in our experimental test set-up.

As a typical COTS example, the optical link with the WDM TTD device was built for a single channel and the RF amplitude and phase ripple was measured for three optical frequencies (around $1550 \mathrm{~nm}$ ) over a 1 $\mathrm{GHz}$ bandwidth at $\mathrm{C}$ band. The optical amplitude ripple was on the order of $0.25 \mathrm{~dB}$ and the phase ripple on the order of 3 degrees for all three optical frequencies. The RF impulse response derived from these errors has a 1 st sidelobe of $-30 \mathrm{~dB}$. However, by calibrating out the modulator and the photodector, we could determine that the ripple is not from the optical but rather the $\mathrm{E} / \mathrm{O}$ and $\mathrm{O} / \mathrm{E}$ components and can probably be improved by choosing better adjusted modulator and photodiode.

\section{Loss}

The availability of erbium amplifiers and the ability for the transmit LFM beamformer to use high modulation index, improves the loss of present day links by many tens of dBs. For instance, assume the previously mentioned phased array with 20 subarrays. We now analyze the loss of the optical beamformer using COTS elements for high modulation depth. The optical input after the modulator was assumed to be $-4 \mathrm{dBM}$. The signal is then amplified via an EFDA amplifier with $30 \mathrm{~dB}$ gain, (26 dBM output power) and split into $20(13 \mathrm{~dB})$. The optical loss in the TTD device is assumed $7 \mathrm{~dB}$. The output signal is directly detected via a photodiode. Using the formula $P_{R F}=m^{2} * 5^{*}\left(\Re P_{\mathrm{op}}\right)^{2} R_{R F}$, where $\Re$ is the responsivity of the diode $(0.8 \mathrm{Amp} / \mathrm{Watt})$ and $\mathrm{R}_{R t}$ is the resistor on receive ( $\left.50 \mathrm{ohms}\right)$, the total effective loss is calculated as $\sum_{i=1,20} \mathrm{P}_{\mathrm{i}, \mathrm{RF}} / P_{R F-\text {-upew }}$ with $P_{i-\mathrm{RF}}=$ the output $\mathrm{RF}$ power from the $i$-th photodetector, and $\mathrm{P}_{\mathrm{RF} \text {-inpot }}=$ the input $\mathrm{RF}$ power into the modulator. For the above, the tota! effective loss is calculated to be $15 \mathrm{~dB}$, approaching values which are acceptable in phased arrays. If the link could only work in the linear region usually with $m<<0.1$, the link loss would be at least $20 \mathrm{~dB}$ lower. Morever, since every optical $\mathrm{dB}$ translates to double in the electrical domain, the presence of the EFDA is of major importance, reducing system loss by several $10 \mathrm{~s}$ of dBs. The advantages of working with high modulation index and an erbium amplifier, when feasible, are immediately apparent.

$\underline{S} / \mathbf{N}$

The signal to noise ratio for an amplified analog link is defined as [7]

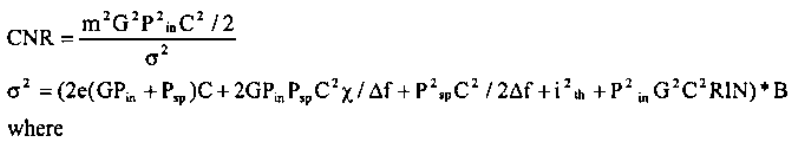

$\mathrm{P}_{\text {in }}=$ input power to optical amplifier, $\mathrm{B}=$ bandwidth, $\mathrm{i}_{\mathrm{th}}=$ thermal noise current spectral density

$\mathrm{P}_{\mathrm{sp}}=$ ASE power emitted by the amplifier $\approx 2(\mathrm{G}-1) \mathrm{h} v \Delta \mathrm{f}, \mathrm{G}=$ amplifier gain

$\chi=$ excess noise figure

$\mathrm{RIN}=$ laser relative intensity noise, $\mathrm{C}=$ Coupling Loss from the amplifier to the detctor

$\Delta \mathrm{f}=$ optical filter after amplifier, $\mathrm{m}=$ modulation depth

The $\mathrm{S} / \mathrm{N}$ depends on the square of the modulation depth. Hence, the ability to work in the non-linear regime of the modulator is critical. The terms in the denominator of Equation (5) are, successively, the shot noise on the photodiode, the signal-spontaneous amplifier noise, the spontaneous-spontaneous amplifier noise, the thermal noise and the RIN of the laser. The $\mathrm{S} / \mathrm{N}$ attributable to thermal noise decreases with decreasing optical power as $1 / P_{n}^{2}$, while the $\mathrm{S} / \mathrm{N}$ dependence on the shot noise decreases as $1 / P_{\text {in }}$. The $\mathrm{S} / \mathrm{N}$ attributable to the signal spontaneous noise and the RIN will dominate for amplified links. The total $\mathrm{S} / \mathrm{N}$ was calculated theoretically for several RINs of the laser and varying optical input power to the amplifier for a $1 \mathrm{MHz}$ bandwidth and the optical beamformer for the phased array defined above, Fig. 3. When the $\mathrm{S} / \mathrm{N}$ of the link in the previous section was measured, the results quite well corresponded to the theorctical calculations. In general, the $\mathrm{S} / \mathrm{N}$ was better than $80 \mathrm{~dB} / \mathrm{MHz}$, which meets many system specifications. 


\section{Conclusions}

Using COTS elements, it is shown that in transmit, at the level of subarrays, photonic beamformers are approaching the level where they can be implemented in real systems.

\section{References:}

(1jH. Zmuda, E.N. Toughlian, M.A. Jones, and P.M. Payson, "Photonic Architectures for Broadband Adaptive Nulling with Linear and Conformal Phased Array Anternas", Fiber and Integrated Optics, Vol. 19 no2. pp. 137-54, 2000

[2] R.J. Mailloux, "Technology for Array Control." IEEE Phased Array Symposium," 2003

[3] R. Rotman, O. Raz and M. Tur, "Requirements for True Time Delay Imaging Systems with Photonic Components," IEEE Phased Array Conference, 2003

[4] Francheschetti G., R. Lanari "Synthetic Aperture Radar," Chapt. 2 , pp. 102, CRC Press, 1999

[5] P. Lacomme, J-P Hardange, J.C. Marchais , and E. Normant, "Air and Spacebome Radar Systems-an Introduction", Chapter 16 pp. 266-271, William Andrew publisher, 2001.

[6] R. Rotman, O. Raz and M. Tur, "The Converson Matrix for Optical Filters with Arbitrary Transfer Function," MWP 2003, Budapest.

[7] Pettitt M.J., "Use of optical amplifiers to increase distribution capacity of optical analogue video systems" IEE Proceedings-J., vol 140, no. 6, pp. 404-410.

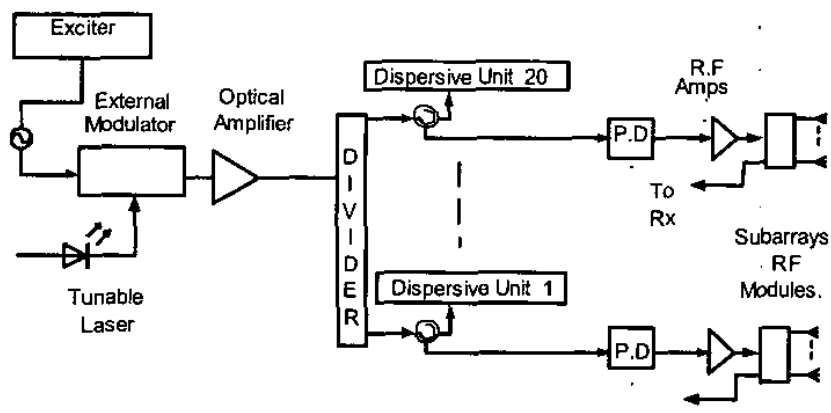

Figurel: Optical Beamforner with RF Subarrays

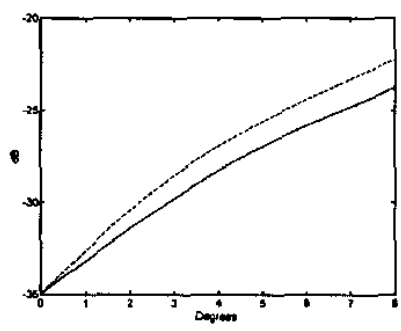

Fig. 2: Peak Sidelobe of Impulse Response vs. Optical Phase Ripple. Solid Line: Modulation Index $=1$ Dashed Line: Modulation Index $=1$

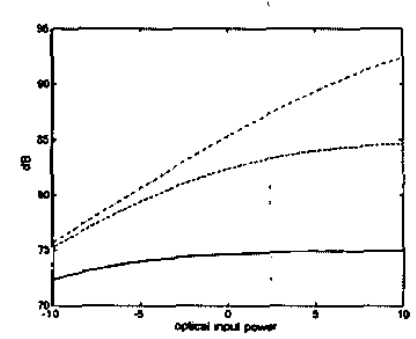

3: SN for Various RINs Solid Line= RIN $135 \mathrm{~dB} / \mathrm{Hz}$, Dashed Line=Rin $145 \mathrm{~dB} / \mathrm{Hz}$, Dashed Dot Line $=$ RIN $155 \mathrm{~dB} / \mathrm{Hz}$ 